\title{
STUDI PENGENDALIAN PEMANAS PADA REAKTOR HIDROGENASI MINYAK NABATI MENJADI GREENDIESEL DENGAN JAKET PEMANAS
}

\author{
Martomo Setyawan \\ Program Studi Teknik Kimia Universitas Ahmad Dahlan \\ Email: $\underline{\text { martomo@che.uad.ac.id }}$
}

\begin{abstract}
Greendiesel is the second generation of the biodiesel fuel. The advantages of greendiesel compare with first generation of biodiesel are higher cetane number, no waste on the production and low $\mathrm{CO}_{2}$ emission. Greendiesel was made from vegetable oil with hydrogenation process at the high temperature and high pressure, this process has high risk to explode. This research was to study about heat transfer mechanism from electric heat source to the reactor with avoid explode, by to avoid hydrogen contact with high temperature above $500^{\circ} \mathrm{C}$.

Heat transfer mechanism on the hydrogenation reactor was designed from electric heat source transferred to the oil heater and then to the reactor. At this research was studied effluence of the electric voltage to the temperature of the heating oil and the water inside at the reactor.

The Result of this research was show increasing voltage cause increasing speed of heating. At the all voltage increasing heating speed occur until 40 minutes as linier and after 40 minutes the heating speed decrease as logarithmic. By indirect heating by electric source contact between hydrogen and high temperature surface can be avoided.
\end{abstract}

\section{Pendahuluan}

Greendiesel adalah bahan bakar alternatif yang merupakan bahan bakar terbarukan dengan kualitas yang lebih bagus dibanding biodiesel. Kelebihan green diesel atau biodiesel G2 ini mampu mencapai bilangan cetane 55 -90 jauh lebih tinggi dari capaian biodiesel G1 yang hanya 40-45, sehingga minyak yang dihasilkan dapat langsung dipakai sebagai bahan bakar mesin diesel tanpa harus ditambahkan dengan solar bahkan tanpa harus melakukan modifikasi mesin. Dengan semakin menipisnya cadangan sumber energ fosil [1,2] green diesel diharapkan mampu menjadi sumber energy alternatif.

Pembuatan green diesel yang tidak menghasilkan limbah sangat efisien secara proses, semua produk dari reaksi antara minyak nabati dan hydrogen merupakan produk yang dapat langsung digunakan. Pembuatan green diesel selama ini digunakan reaktor batch, tekanan 20-30 atm dan suhu antara 200-300 ${ }^{0} \mathrm{C}$.

Reaksi pembuatan greendiesel adalah reaksi hidrogenasi pada suhu dan tekanan tinggi. Hidrogen sebagai salah satu bahan baku greendiesel adalah bahan yang mudah terbakar dan dapat terbakar sendiri pada suhu $500{ }^{\circ} \mathrm{C}$. Pemanasan reaktor hidrogenasi untuk mendapatkan suhu operasi diperlukan pemanas dengan suhu lebih dari $500{ }^{\circ} \mathrm{C}$.Reaktor yang digunakan pada penelitian ini adalah alat yang dirancang dan dibuat sendiri, untuk merancang reaktor hidrogenasi yang aman maka pemahaman karakteristik proses pemanas berupa kecepatan pemanasan dan suhu operasi yang dicapai dan pengendaliannya diperlukan untuk menjaga keamanan proses.

Penelitian ini bertujuan untuk mempelajari mekanisme dan karakteristik perpindahan panas dari elemen pemanas listrik ke jaket pemanas, mempelajari mekanisme dan karakteristik perpindahan panas dari jaket pemanas ke dalam reaktor dan mempelajari mekanisme pengendalian proses reaktor berpengaduk dan berpemanas.

Reaksi pembuatan green diesel dengan hidrogenasi minyak nabati telah diteliti oleh banyak peneliti, pada tahun 2007 percobaan hidrogenasi minyak nabati menghasilkan alkana, rantai gliserol dari trigliserida dihidrogenasi menghasilkan propane dan tidak terbentuk gliserol, minyak setara minyak diesel yang dihasilkan bukan berupa oksigenat seperti hasil transesterifikasi tapi berwarna jernih dan memiliki angka cetane yang tinggi antara 85 sampai 99 [3]. 
Penelitian mereaksikan hidrogen dengan minyak nabati telah dilakukan oleh Kubicka[4]. Yaitu mengadakan penelitian tentang perubahan minyak nabati menjadi hidrokarbon dengan katalis mesoporous alumina supported menjadi hidrokarbon dengan Cobalt Molybdenum (CoMo) katalis, hasil penelitian menyimpulkan konversi trigliserida tertentu menjadi hidrokarbon pada suhu $310{ }^{0} \mathrm{C}$ dan tekanan $7 \mathrm{Mpa}$, katalis Organized Mesoporous Alumina (OMA) menunjukan kinerja lebih bagus dibanding katalis industrialalumina-base. Dua jenis reaksi yang terjadi :hydrodeoxygenation dan hydrodecarboxylation.

Penggunaan CoMo/ $\mathrm{Al}_{2} \mathrm{O}_{3}$ katalis diteliti oleh Krar [5] untuk mereaksikan minyak bunga matahari dan diperoleh hasil paraffin yang panjang setara dengan diesel. Pada suhu $380{ }^{\circ} \mathrm{C}$, tekanan $40-60$ bar, dengan perbandingan $\mathrm{H}_{2}$ dan Minyak $500-600 \mathrm{Nm}^{3} / \mathrm{m}^{3}$

Pemanas untuk memanaskan reaktor dapat dilakukan dengan memasang selubung (jaket) pemanas [6]. Sumber panas dapat digunakan elemen pemanas listrik [7]. Besarnya panas yang timbul dari energi listrik setara dengan tegangan listrik dikali dengan kuat arus

Pengendalian proses adalah upaya menjaga supaya proses kimia mengalami gangguan, untuk kasus tangki pemanas maka model pengendalian proses sebagai berikut :

$$
T^{\prime}(s)=\left(\frac{K}{\tau s+1}\right) Q^{\prime}(s)
$$

\section{Metodologi}

Penelitian ini dilakukan di laboratorium Teknik Kimia UAD, Bahan penelitian ini berupa Minyak pemanas (oil bath), Air dan udara tekan, alat penelitian berupa serangkaian reactor dengan pemanas seperti gambar dibawah ini

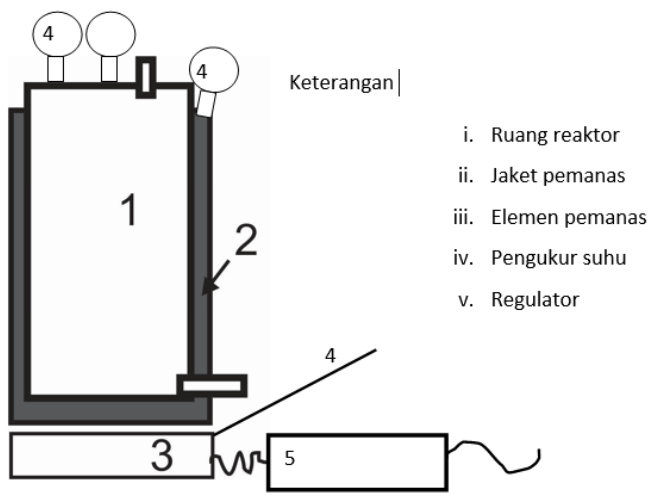

Gambar 1. Skema alat penelitian

Untuk mempelajari karakter perpindahan panas dari elemen listrik ke jaket pemanas dilakukan dengan melakukan variasi tegangan listrik dan mengukur suhu elemen pemanas listrik dan jaket pemanas dengan variasi fluida pemanas. Dengan langkah langkah Masukkan fluida pemanas dalam jaket pemanas, kemudian Sambungkan Pemanas Listrik Melalui regulator tegangan, Hidupkan regulator untuk 100 volt, Catat suhu Pemanas Listrik dan suhu pemanas oli tiap 5 menit sampai kondisi ajeg. Ulangi untuk voltase 125, 150, 175, 200 dan 220 volt

Untuk Mempelajari karakter perpindahan panas dari jaket pemanas kedalam reaktor dilakukan dengan melakukan variasi tegangan listrik dan mengukur suhu jaket pemanas dan dalam reaktor dengan variasi fluida dalam reaktor .Langkah sebagai berikut masukkan fluida pemanas dalam jaket pemanas sebanyak 500 cc, Sambungkan Pemanas Listrik Melalui regulator tegangan, Nyalakan pemanas dengan tegangan 100 volt, Catat kenaikan suhu pemanas dan fluida dalam reactor. Ulangi untuk volume pemanas yang berbeda-beda $1000 \mathrm{ml}, 1500 \mathrm{ml}$ dan $2000 \mathrm{ml}$. dan ulangi untuk volume fluida yang berbeda-beda

Data hasil percobaan berupa data suhu dan waktu diolah untuk mengetahui Suhu pemanas fungsi waktu dan kecepatan pemanasan dengan metode regresi linier. Untuk kecepatan pemanasan dihitung waktu untuk mencapai suhu pemanas $500^{\circ} \mathrm{C}$ 
Chemica

Volume 1, Nomor 1, Juni 2014, 27-32

ISSN : 2355-8776

model

Untuk menentukan konstanta waktu pengendalian maka permasalahan pemanasan didekati dengan

$$
\text { Dengan } \begin{gathered}
\mathrm{T}_{(\mathrm{t})}=\mathrm{T}_{\max }\left(1-\mathrm{e}^{(-\mathrm{t} / \tau)}\right) \\
\mathrm{T}=\text { suhu } \\
\\
\mathrm{t}=\text { waktu, menit } \\
\tau=\text { konstanta waktu }
\end{gathered}
$$

Konstanta waktu dicari dengan pendekatan kesalahan kuadrat terkecil ( SSE) dari T data dan suhu terhitung, dengan melakukan minimasi menggunakan fasilitas solver dalam Microsoft excel maka nilai konstanta waktu dapat dihitung.

\section{Hasil Penelitian dan Pembahasan}

Pengaruh tegangan terhadap Suhu elemen Pemanas, Panas yang ditimbulkan berbanding dengan tegangan yang listrik yang diberikan. Hasil percobaan pengaruh tegangan terhadap panas sebagai fungsi waktu dapat dilihat pada grafik berikut:

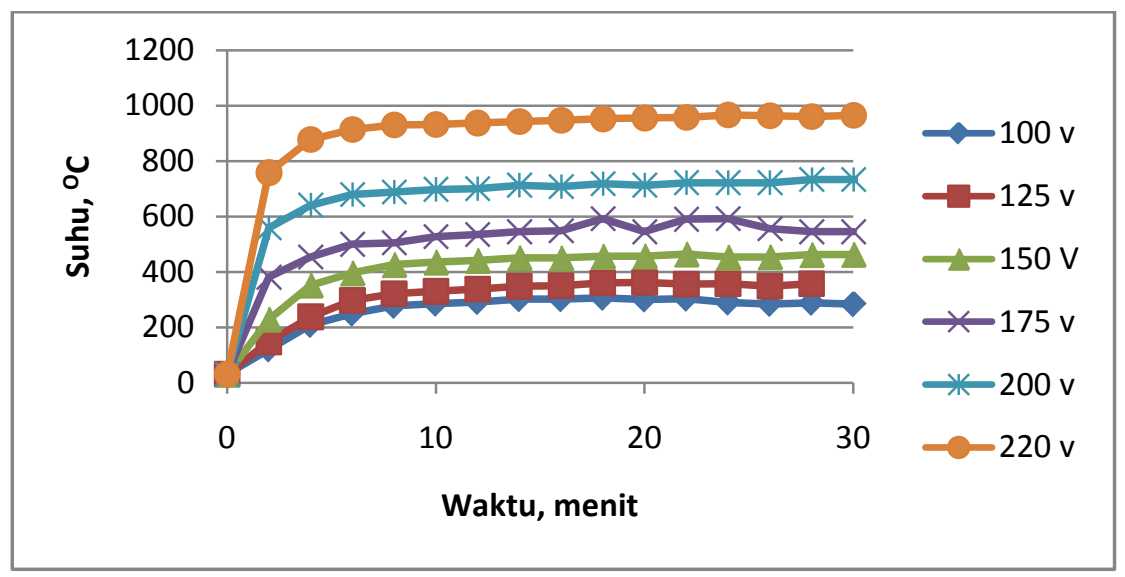

Gambar 2. Grafik Hasil percobaan suhu dan tegangan listrik

Dari data dapat dihitung bahwa tegangan listrik mempengaruhi suhu maksimal pemanas, dan dapat dilihat seperti grafik berikut

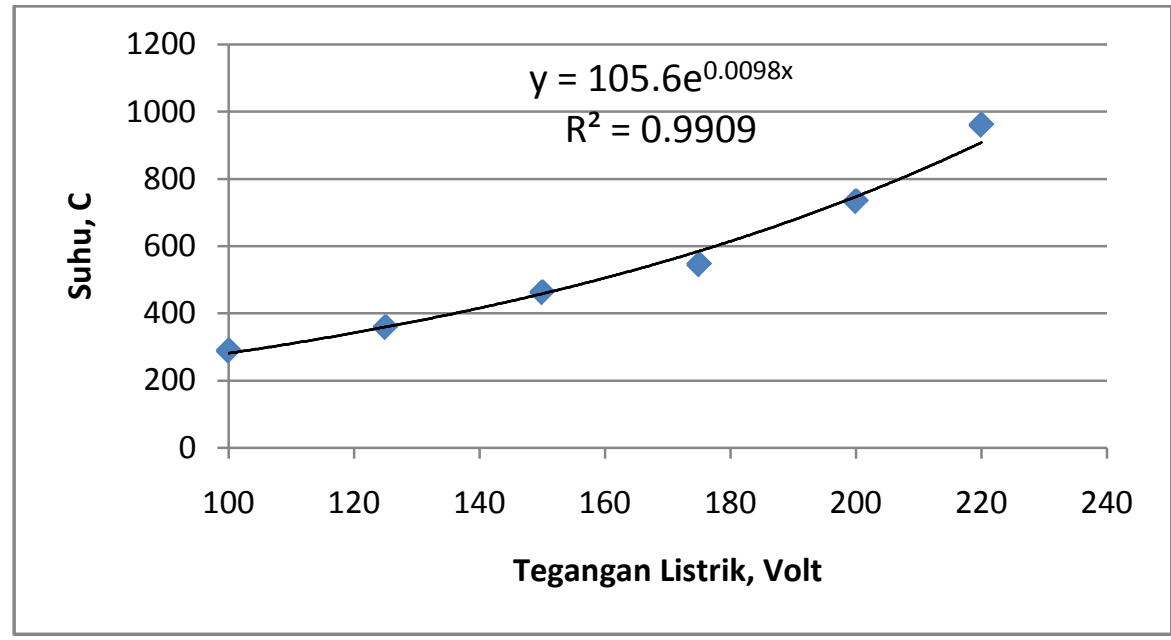

Gambar 3. Suhu pemanas fungsi tegangan listrik

Persamaan empirik yang mewakili suhu pemanas fungsi tegangan listrik adalah $\mathrm{T}=105.6 \mathrm{e}^{0.0098 \mathrm{~V}}$, dengan ketepatan $99 \%$

Berdasarkan data pemanasan tiap tegangan, dapat dihitung konstanta waktu dengan persamaan umum 


$$
\mathrm{T}_{(\mathrm{t})}=\mathrm{T}_{\max }\left(1-\mathrm{e}^{(-\mathrm{t} / \tau)}\right)
$$

Perhitungan mencari konstanta waktu berdasarkan persamaan diatas dengan prinsip minimasi Sum of Square of Error, diperoleh hasil sebagai berikut

Tabel 1. Hasil perhitungan konstanta waktu

\begin{tabular}{|c|c|c|}
\hline No & Tegangan Listrik, Volt & Konstanta Waktu, menit \\
\hline 1 & 100 & 2,95 \\
\hline 2 & 125 & 3,63 \\
\hline 3 & 150 & 2,98 \\
\hline 4 & 175 & 1,94 \\
\hline 5 & 200 & 1,58 \\
\hline 6 & 220 & 1,37 \\
\hline
\end{tabular}

Dari tabel 1 terlihat bahwa semakin besar tegangan listrik memiliki konstanta waktu yang semakin kecil, hal ini berarti semakin besar tegangan pengaruh tegangan listrik semakin cepat.

Data hasil percobaan pengaruh tegangan listrik terhadap suhu pemanas oli sebagai berikut

Tabel 2. Hasil Pengukuran suhu pemanas dan air dalam reaktor

\begin{tabular}{|c|c|c|c|c|}
\hline \multirow{2}{*}{$\begin{array}{l}\text { T, } \\
\text { Menit }\end{array}$} & \multicolumn{2}{|c|}{ V= 100} & \multicolumn{2}{c|}{ V=125 } \\
\hline 0 & 37 & 30 & Suhu oli, ${ }^{\circ} \mathrm{C}$ & Suhu air dalam, ${ }^{\circ} \mathrm{C}$ \\
\hline 10 & 39 & 31 & 35 & 26 \\
\hline 20 & 41 & 35 & 35 & 29 \\
\hline 30 & 50 & 41 & 37 & 32 \\
\hline 40 & 56 & 47 & 50 & 45 \\
\hline 50 & 60 & 54 & 65 & 55 \\
\hline 60 & 62 & 57 & 80 & 70 \\
\hline 70 & 65 & 60 & 89 & 76 \\
\hline 80 & 66 & 61 & 97 & 84 \\
\hline 90 & 70 & 65 & 109 & 90 \\
\hline 100 & 76 & 66 & 120 & 99 \\
\hline 110 & 76 & 67 & 128 & 101 \\
\hline 120 & 80 & 70 & 130 & 106 \\
\hline 130 & 85 & 75 & 136 & 110 \\
\hline 140 & 90 & 76 & 140 & 114 \\
\hline 150 & 95 & 77 & 150 & 115 \\
\hline 160 & 98 & 80 & 154 & 119 \\
\hline 170 & 100 & 81 & 156 & 120 \\
\hline 180 & 103 & 82 & 160 & 122 \\
\hline 190 & 105 & 85 & 160 & 125 \\
\hline 200 & 105 & 86 & 163 & 121 \\
\hline 210 & 106 & 86 & 165 & 125 \\
\hline 220 & 110 & 88 & 164 & 125 \\
\hline 230 & 110 & 90 & & \\
\hline 240 & 110 & 90 & & \\
\hline & & & & \\
\hline
\end{tabular}

Dari tabel diatas dapat dihitung konstanta waktu 
Tabel 3. Hasil perhitungan konstanta waktu pengaruh tegangan listrik terhadap suhu oli pemanas dan air dalam reaktor

\begin{tabular}{|c|c|c|}
\hline \multirow{2}{*}{ Tegangan Listrik } & \multicolumn{2}{|c|}{ Konstanta waktu } \\
\cline { 2 - 3 } & Oli Pemanas & Air dalam reaktor \\
\hline 100 & 72,72 & 64.1 \\
\hline 125 & 68,15 & 59,56 \\
\hline
\end{tabular}

Dari tabel 3 terlihat bahwa tegangan listrik mempengaruhi konstanta waktu pemanasan oli pemanas dan air, bahwa semakin tinggi tegangan maka konstanta waktu akan semakin pendek, apabila dibandingkan antara konstanta waktu pemanasan oli dan air maka konstanta waktu oli lebih lama dibanding air hal ini disebabkan panas yang diterima oli tidak hanya untuk memanaskan oli akan tetapi diteruskan untuk memanaskan air.

Berdasarkan data pada table 2, maka dapat dihitung pengaruh tegangan terhadap kecepatan pemanasan oli pemanas dan air dalam reactor sebagai berikut, secara umum kecepatan pemanasan meningkat sampai waktu 40 menit, semakin tinggi tegangan listrik semakin cepat perubahannya seperti terlihat pada gambar 8 berikut.

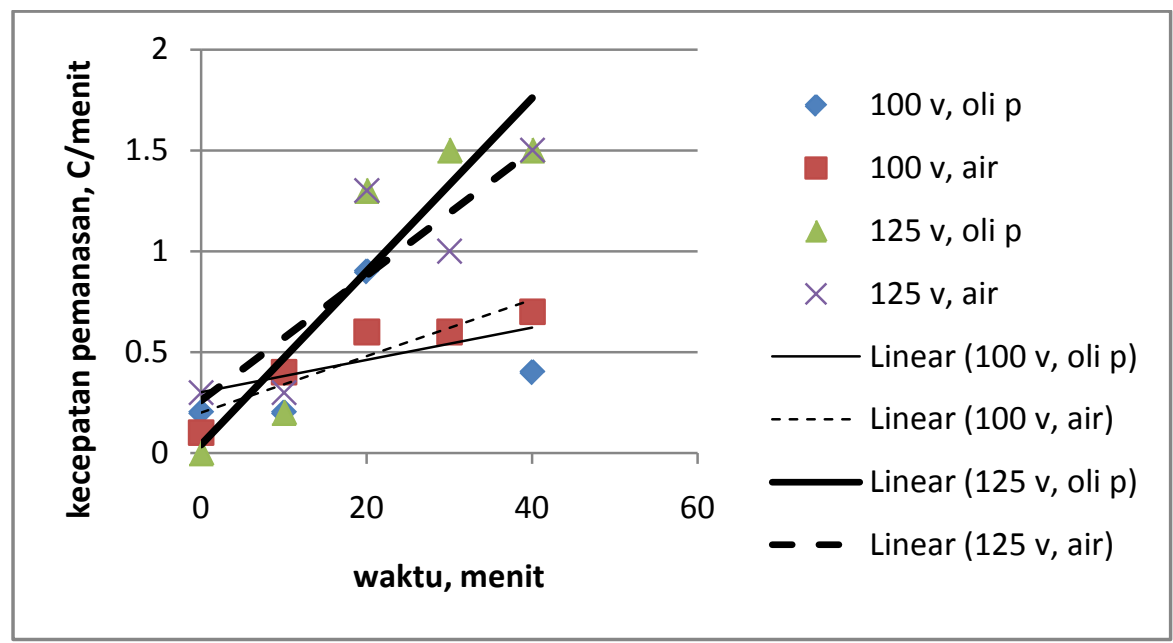

Gambar 4 Grafik kecepatan pemanasan dibawah 40 menit

Setelah waktu 40 menit kecepatan pemanasan cenderung menurun secara logaritmis seperti terlihat dalam gambar 9 berikut

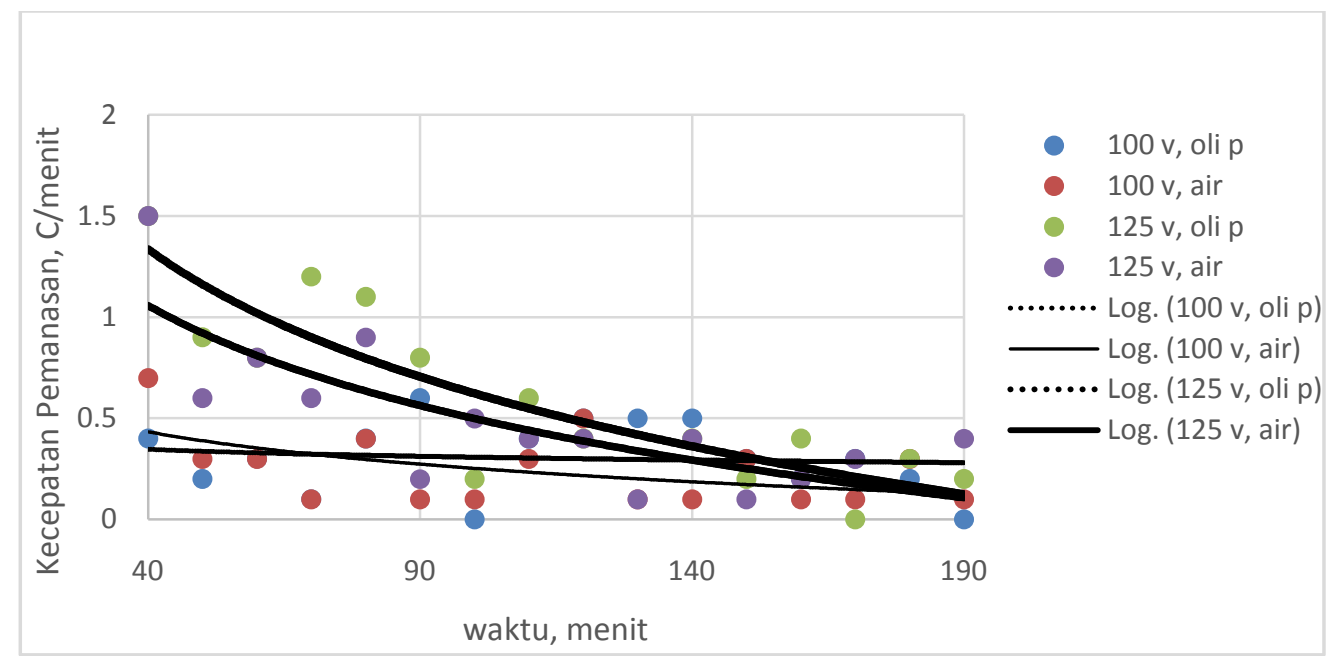

Gambar 9 Grafik kecepatan pemanasan di atas 40 


\section{Kesimpulan}

Dari penelitian dapat disimpulkan

1. Semakin besar tegangan listrik suhu pemanas semakin tinggi dengan persamaan $T=105.6 \mathrm{e}^{0.0098 \mathrm{~V}}$, dengan ketepatan $99 \%$.

2. Semakin besar tegangan listrik perubahan suhu pemanas semakin cepat hal ini dibuktikan dengan semakin kecilnya konstanta waktu pemanasan berturut turut dengan tegangan listrik sebagai berikut 100, 125, 150, 175, 200 dan 220 v diperoleh konstanta waktu sebagai berikut 2,95; 3,63; 2,98; 1,94; 1,58 dan 1,37 menit

3. Mekanisme perpindahan panas dari pemanas listrik ke oli pemanas dan air akan meningkat kecepatannya dengan semakin tingginya tegangan listrik.

4. Kecepatan pemanasan meningkat secara linier sampai waktu 40 menit dan turun secara logaritmis setelah 40 menit.

\section{Daftar Pustaka}

1. Kurtubi, 2004 ,Indonesia : Net Oil Importer, Center for Petroleum and Energy EconomicsSudies (CPEES), Jakarta

2. Shafizadeh F, 1982, Chemistry of Pyrolysis and Combustion of Wood, in Proceedings: 1981 International Conference on Residential Solid Fuels - Environmental Impacts and Solutions, Cooper JA, Malek D eds, Oregon Graduate Center, Beverton: 746-771.

3. Snare, M., Arvela, P.M., Simakova, I.L., Myllyoja, J., and Murzin, D.Y., 2009, Overview of Catalytic Methods for Production of Next Generation biodiesel from Natural Oil and Fats, Russian Journal of Physical Chemistry, vol 3 no 7, pp 1035-1043

4. Kubicka, D., Simacek, P., and Zilkova, N., 2009, Transformation of Vegetable Oils into Hydrocarbon Over Mesoporous-Alumina-Supported CoMo Catalyst, Top Catalyst(2009) 52:161-168

5. Krar, M., Kovacs, S., Kallo, D., and Hancsok, J., 2010, Fuel purpose hydrotreating of sunflower oil on CoMo/Al2O3 catalyst, Bioresource Technology 101 (2010) 9287-9293

6. Levenspiel, O., 1999, Chemical Reaction Engineering, John Wiley and sons, New York

7. Perry, R.H., and Green, D.W., 1999, Perry's Chemical Engineers' Handbook, Mc Graw Hill, New York 